\title{
Does anthracycline-based chemotherapy in pregnant women with cancer offer safe cardiac and neurodevelopmental outcomes for the developing fetus?
}

\author{
Marialuisa Framarino-dei-Malatesta ${ }^{1 *}$ (D), Paolo Sammartino ${ }^{2}$ and Angela Napoli, ${ }^{3,4}$
}

\begin{abstract}
Background: Cancer treatment during pregnancy is a growing problem especially now that women delay childbearing. Systemic treatment of these malignancies during pregnancy centers mainly on the anticancer drugs anthracyclines, widely used in treating hematological and breast cancer during pregnancy and sometimes associated with early and late toxicity for the fetus. Owing to concern about their cardiac and neurodevelopmental toxicity more information is needed on which anthracycline to prefer and whether they can safely guarantee a cardiotoxicity-free outcome in the fetus.

Discussion: The major research findings underline anthracycline-induced dose-dependent effects, including cardiotoxicity, many avoidable. Partly because the placenta acts mainly as a barrier, research findings indicate low transplacental anthracycline transfer. Anthracycline-induced teratogenicity depends closely on when patients receive chemotherapy. Anthracycline cardiac toxicity may depend on the association with drugs that inhibit or induce placental P-glycoprotein (P-gp). P-gp-induced drug interactions may alter placental P-gp barrier function and subsequently change fetal exposure. Though many anthracyclines have acceptable safety profiles clinical studies suggest giving idarubicin with special caution. Patients and doctors who care for pregnant women should whenever possible avoid prematurity and hence reduce prematurity-induced medical complications at birth and in the long-term. Information is lacking on longterm anthracycline-induced effects.
\end{abstract}

Conclusion: Pregnant women receiving anthracycline-based chemotherapy should undergo regular, state-ofthe-art diagnostic imaging to detect fetal drug-induced cardiac damage early, and allow alternative therapeutic options. Recognizing drug-induced interactions and understanding the most vulnerable fetuses will help in choosing tailored therapy. Future research on placental transport, blood-brain barrier drug passage and pharmacokinetics will improve the way we manage these difficult-to-treat patients and their fetuses.

Keywords: Anthracyclines, Cancer pregnancy, Anthracycline cardiotoxicity, Neurodevelopmental outcomes

\section{Background}

Though cancer during pregnancy is a rare event, affecting only 1 in 1000 to 1 in 1500 pregnancies [1], deciding on anticancer drug treatment options for pregnant women is a challenging task. Given the current general trend for women in developed countries to delay childbearing, treating cancer in pregnant women is also a growing problem [2].

\footnotetext{
* Correspondence: marialuisa.framarino@gmail.com

${ }^{1}$ Department of Gynecologic Obstetrics and Urologic Sciences, University

Sapienza Rome, Viale del Policlinico, 15500161 Rome, Italy

Full list of author information is available at the end of the article
}

Breast cancer in pregnancy accounts for $0.7 \%$ of all breast cancer cases, as reported in studies from western countries $[3,4]$. Hematological cancers are less frequent than breast cancer in pregnancy [5].

Systemic treatment of these malignancies during pregnancy centers mainly on the anticancer drugs anthracyclines. Anthracyclines are widely used in treating hematological and breast cancer during pregnancy and sometimes associated with early and late toxicity for the fetus.

Up-to-date, comprehensive information is needed on which anthracycline to choose for treating pregnant 
women with cancer, how to use these potentially teratogenic medications during pregnancy, and how to reduce the risks of fetal toxicity. In this overview, to help gynecologists, oncologists and obstetricians who take difficult decisions on anticancer therapy for pregnant patients we assess major research findings on placental drug transfer, consider possible teratogenicity and cardiotoxicity and suggest directions for future research.

\section{Methods}

In this review, we searched PubMed and Medline for English language papers focusing on anthracycline use for cancer in pregnancy published from 1975 to 2011 using the search terms anthracyclines, transplacental anthracycline transfer, cancer in pregnancy, anthracycline cardiac toxicity, and anthracycline-related neurodevelopmental toxicity. We included research articles, reviews, case reports and consensus statements. Potential, relevant studies were further identified by the article title and abstract and then assessed in detail.

\section{Discussion}

Through what anticancer mechanisms do anthracyclines act? Anthracyclines act against widely ranging solid tumors and hematological malignancies by inducing complex and multiple patterns of DNA damage in anthracyclinetreated cancer cells [6]. Anthracycline-induced cytotoxic activity involves multiple pathways: one is topoisomerase II inhibition, induced when the 9,10- anthraquinone ring intercalates between adjacent DNA base pairs causing the formation of single and double-strand protein-associated DNA [7]. By interacting with the topoisomerase-II-beta enzyme, impaired DNA repair has an important role in modulating DNA double helix supercoiling, and produces hydroxyl radicals (OH-) causing antitumor effects and toxicity to healthy tissues [8].

Some evidence suggests that these radicals are produced via poly (ADP-ribose) polymerase (PARP) and nicotinamide adenine dinucleotide phosphate (NADPH) oxidase causing the caspase hyperactivation that is essential for cell apoptosis or programmed cell death [9]. Despite their anticancer activity, anthracycline tolerability is limited by cardiotoxicity, a dose-dependent effect that can cause irreversible cardiomyopathy and congestive heart failure.

Given that cardiomyocytes do not replicate, anthracycline presumably induces dose-dependent cardiotoxicity, which can cause irreversible heart failure through molecular mechanisms other than DNA synthesis. Because reducing mitochondrial iron levels protects against doxorubicin (DOX)induced cardiomyopathy its cardiotoxicity could reflect interactions with cellular iron metabolism causing mitochondrial iron accumulation [10]. Differences in the ability of some iron chelators in lowering DOX-induced cardiotoxicity could reflect their varying effectiveness in decreasing mitochondrial iron [11].

The mechanisms responsible for anthracycline-induced cardiotoxicity also include altered cell membrane fluidity and ion transport generating reactive oxygen species (ROS) from iron anthracycline complexes, leading to lipid peroxidation and membrane damage [12]. Fibrillar and structural protein network remodeling involving the so-called extracellular matrix activated by anthracycline-induced activity contributes to cardiac damage [13] (Figure 1).

Two specific developmental features explain why anthracycline induces cardiotoxicity in the fetus. First, fetal cardiac tissue is especially vulnerable to free radical damage owing to low cardiomyocyte tolerance to changes in the oxidantantioxidant system [14]. Second, the fetal myocardium is especially vulnerable to chemotherapy-induced damage because embryonic and fetal myocytes are smaller than those in adults and their force-generating ability increases only over time during prenatal life when contractile proteins develop and undergo structural organization [15].

\section{Placenta: Barrier or filter? Hints from pharmacokinetics}

The extent of placental transfer and fetal drug concentration depend on the molecular weight, physicochemical drug properties such as lipid solubility, maternal concentration, fetal drug clearance, differences in drug binding protein and the $\mathrm{pH}$ at which the drug is ionized. Lowmolecular-weight $(<500 \mathrm{Da})$, lipid-soluble and unbound compounds can easily cross the human placenta [16].

Even though the physical and chemical drug characteristics can drive transplacental passage, observations in recent years attribute placental permeability to various active efflux transporters such as P-glycoprotein (P-gp), a $170 \mathrm{kDa}$ membrane protein belonging to the ATPbinding cassette superfamily, highly expressed in apical syncytiotrophoblast [17].

Through the energy supplied by ATP hydrolysis, P-gp acts as a pump able to remove drugs from the cell membranes and cytoplasm thus preventing cytotoxic compounds present in the maternal circulation from entering the placenta [18]. The breast cancer resistance protein (BCRP), another active transporter, expressed at the apical surface of the syncytiotrophoblast, also transports many substrates including anthracyclines and other chemotherapeutic agents [19]. In the large group of ATP-binding cassette transporters with 52 members, 3 other proteins are heavily involved in drug transport: $A B C C 1,2,3$ or MRP 1,2,3 [20, 21]. Their expression profile varies with advancing gestation [22], transcription factors, steroid hormones [23], and inflammatory pathways [24]. Genetic variations in the genes encoding these drug transporters modulate drug transporter expression [25]. Drug transporter protein expression and activity in the placenta may change during gestation and is tightly regulated by many 


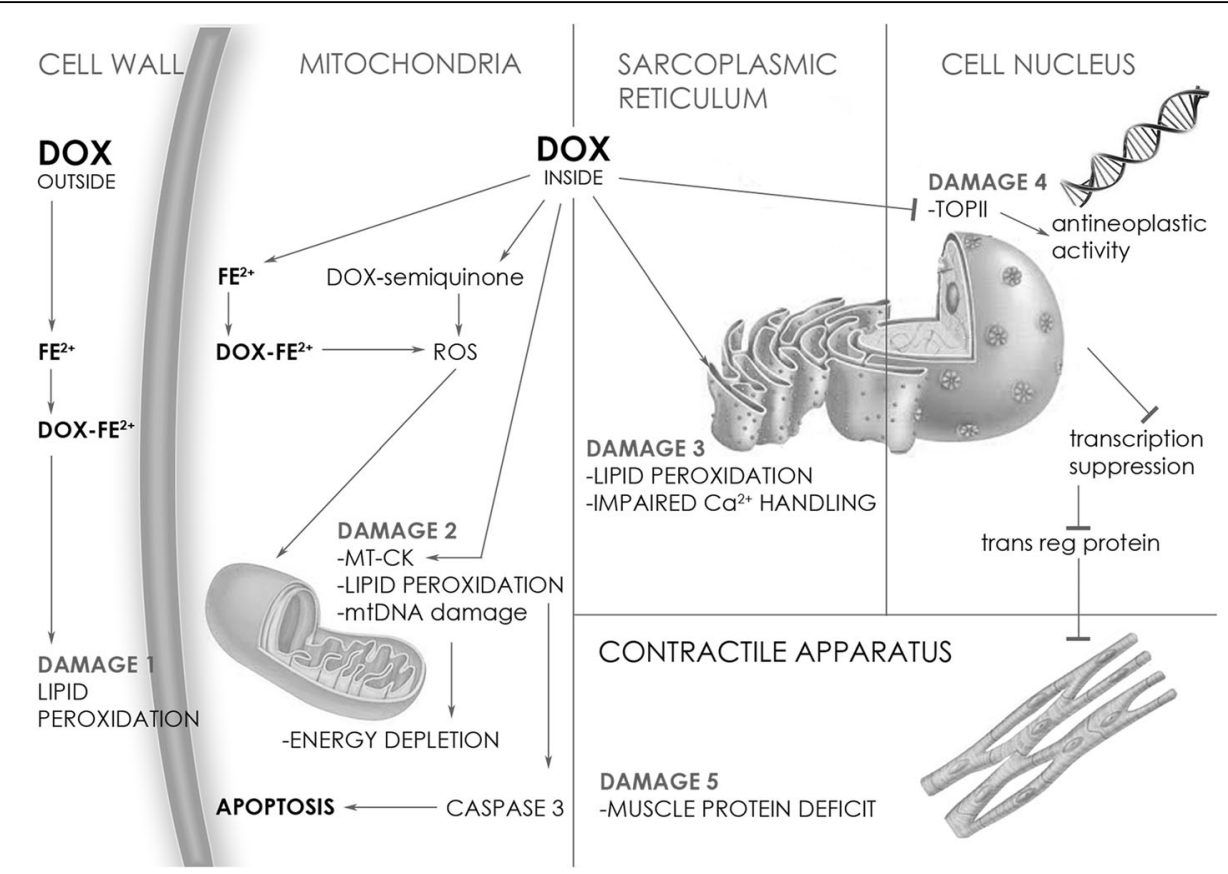

Fig. 1 The mechanism underlying anthracycline-induced myocyte toxicity. DOX: doxorubicin; MT-CK: mitochondrial creatine kinase; Fe ${ }^{2+}$ : iron; ROS: reactive oxygen species; $\mathrm{Ca}^{2+}$ : calcium; TOPII: topoisomerase II; trans reg protein: transcriptional regulatory protein. Outside the cell DOX forms iron anthracycline complexes inducing membrane lipid peroxidation. After entering into the cell, DOX by interacting with the topoisomerase-II-beta enzyme, impairs DNA transcription, sarcoplasmic reticulum and muscle proteins. ROS production interacts with cellular iron metabolism causing mitochondrial iron accumulation and toxicity to mitochondrial functioning

factors. In syncytiotrophoblasts, transporters are found both in the apical membrane facing maternal blood and basolateral membrane close to fetal capillaries. The human placenta is nevertheless structurally complex and in vitro models may not overlap with human models owing to the morphologically heterogenous placentas in the various species and in their differing membrane transporter expression. Hence placental drug transporters need more detailed preclinical and clinical studies. Current evidence therefore implies that the placenta acts mainly as a barrier and less as a filter.

\section{Transplacental anthracycline transfer}

Studies designed to assess fetal exposure to chemotherapeutic drugs including anthracyclines have reported their transplacental transfer from mother to fetus. In vivo data on transplacental drug transfer in pregnant women only partly overlap in vitro published data owing to interindividual genetic and metabolic differences responsible for pharmacokinetic and pharmacodynamic variabilities in pregnancy.

The first studies on transplacental passage of DOX and epirubicin (EPI) date back to 1975 when these drugs were introduced for treating various neoplastic disorders, in particular breast and hematological cancers [26]. Because all the anthracyclines except idarubicin have a molecular weight larger than $500 \mathrm{Da}$ and high plasma protein binding (50-85\%), they presumably have a low transplacental passage. DOX given at low doses resulted in undetectable drug levels in amniotic fluid, fetal brain or gastrointestinal tract [27] or in cord blood from a healthy child born $48 \mathrm{~h}$ after treatment [28]. Neither DOX nor its metabolites were detected in amniotic fluid, collected through amniocentesis in a 31-year-old woman at 28 weeks treated weekly with DOX chemotherapy [29]. DOX achieved low global transfer values $(2.96 \% \pm 0.75 \%)$ and seemed not to be dose-dependent also in vitro studies [30]. The mean EPI transfer value through the human placenta perfused at fetal and intervillous spaces by Earle's liquid was even lower than that for DOX showing less placental toxicity than DOX [31]. Daunorubicin was found at low concentrations in liver, kidney and lung from a dead fetus from a mother with acute myeloid leukemia [32].

Kinetic studies designed to reproduce the placental circulation in women began on animal models. Transplacental transfer of DOX, EPI, and daunomycin was reproduced in a mouse model showing that fetal anthracycline levels were much lower than maternal levels $(5.1 \pm 0.6 \%, 4.8 \pm 3.8 \%, \quad 13.3 \pm 3.5 \%)$ [33]. Fetal blood samples from pregnant rats receiving DOX contained a plasma concentration $6.2 \%$ that of the mother. Hence fetal DOX exposure left heart microstructure or cellular DNA turnover and apoptosis unchanged [34]. 
Subsequently, transplacental passage of anthracyclines in animal models was studied for the most frequently applied combination regimens. The milestone in this research remains the collection of fetal and maternal blood samples, amniotic fluid, urine, fetal and maternal tissues, and cerebrospinal fluid in the baboon pregnant model treated with fluorouracil-EPI-cyclophosphamide (FEC) and DOX-bleomycin-vinblastine-dacarbazine (ABVD). Fetal plasma concentrations of DOX and EPI averaged $7.5 \pm 3.2 \%$ and $4.0 \pm 1.6 \%$ of maternal concentrations [35].

Unlike other anthracyclines, idarubicin is more lipophilic and a less avid substrate for P-gp, chemical properties that may explain its higher efficacy in chemoresistant tumors [36] and greater transplacental transfer. This biochemical feature probably involves a lack of a host defense mechanism against this harmful substance causing fetal toxicity.

The clinically approved liposomal DOX formulations, non-pegylated (PL) liposomal DOX and PL liposomal DOX, were introduced to reduce anthracycline-induced adverse effects [37]. Human placental perfusion studies showed that like DOX, non-PL liposomal DOX has low transfer kinetics from maternal to fetal circulation whereas PL-DOX proved undetectable in the fetal circulation being extremely low in the perfused placental tissue [38].

These research results indicating low transplacental anthracycline transfer prompted clinical studies to corroborate previous findings.

\section{Anthracyclines in human pregnancy Teratogenic risks}

In general, the teratogenic effect of chemotherapeutics depends on several factors including the stage of embryonic development. From conception until implantation ( 2 weeks) insults to the embryo are likely to result in death and miscarriage or in intact survival because the embryo is undifferentiated and damage can be repaired as remaining totipotent cells multiply to replace those which have been lost [39].

Chemotherapy administered during organogenesis from 4 to 13 weeks of pregnancy is associated with an increased risk of miscarriage or congenital malformation. In this period tissues are highly sensitive to teratogenicity not only because they differentiate rapidly but also because damage to them becomes irreparable. The heart, neural tube and limbs are affected earlier than the palate and ear [40, 41]. Exposure to chemotherapeutics during the second and third trimester after organogenesis ends, does not usually increase the teratogenic risk.

Another factor influencing drug teratogenicity is pharmacokinetics. The increased blood volume (by almost 50\%), and renal clearance during pregnancy, might for example decrease active drug concentrations
[42]. If the mixed oxidase system in the liver worked faster it could also help reduce drug concentrations. And gastrointestinal functional changes may alter drug absorption $[43,44]$.

The third factor influencing teratogenicity is the drug class. A systematic review assessing outcomes in patients with acute myeloid leukemia during pregnancy reported 2 fetal deaths in 4 mothers receiving cytarabine and daunorubicin in the first trimester, whereas in 38 women who began therapy in the second trimester there were 3 fetal deaths and 2 malformations: adherence of the iris to the posterior cornea and hypospadias [45]. In pregnant patients under combined therapy with cytarabine and idarubicin the rate of fetal defects was $28.6 \%$ and the death rate was $12.5 \%$ [45]. In a series of seven babies whose mothers received idarubicin in the second trimester for acute myeloid leukemia one showed limb defects such as shallow sacral dimples, short digits and limbs and prominent frontal skull with macrognathia [46].

A French survey addressing the anthracylines DOX and EPI reported 20 patients with breast cancer in pregnancy treated with combined anthracycline-based chemotherapy [47]. Two pregnancies in women undergoing chemotherapy during the first trimester resulted in spontaneous abortion. One pregnancy in a woman undergoing chemotherapy in the second trimester resulted in intrauterine death and 1 newborn died 8 days after birth for no known reason. In these patients, the multiagent chemotherapy regimen included EPI [47]. Another fetus died after second trimester exposure to epirubicin, vincristine and prednisone [48].

The largest case-control observational study including 413 women from 7 European countries with a primary diagnosis of breast cancer during pregnancy later established that DOX and EPI administered during the second trimester do not increase the teratogenic risks. In a series of 197 patients, 178 received EPI (102) or DOX (76) during pregnancy and of the 386 infants born, only 9 (2\%) had malformations (8 in infants exposed to chemotherapy) [49].

Other clinical studies have also shown that DOX and EPI-based chemotherapy in the second and third trimesters can be administered with minimal teratogenic risk to the developing fetus. Hence international guidelines consider these anthracycline regimens safe and should be offered according to management protocols defined by the risk of breast cancer relapse and mortality $[50,51]$. Conversely, the reported idarubicin-induced teratogenicity suggests that gynecologists and oncologists should prescribe this drug only with caution when no alternative exists for pregnant mothers with cancer, especially those with hematological cancer. 


\section{Pregnancy complications}

Second and third trimester anthracycline exposure may increase the risk of pre-term labor and low birth weight. In the French survey delivery was timed at a mean 34.7 weeks ( \pm SD 2.2 weeks) with two newborns having complications related to prematurity (transient respiratory distress) [47]. In their study, Hahn et al. extended previous evidence from the MD Anderson Cancer Center [52] by reporting 57 pregnant breast cancer patients treated with fluorouracil-DOX-cyclophosphamide (FAC) in an adjuvant (n. 32) or neoadjuvant (n. 25) setting [53]. Most patients delivered at a gestational age of at least 34 weeks (average 37 weeks, range 29-42) and 28\% of the newborns had difficulty in breathing [53]. A series of 103 breast cancer pregnant patients receiving anthracycline-based treatment delivered at a mean gestational age of $35.8 \pm$ 1.9 weeks with birth weight $2836 \pm 1075 \mathrm{~g}$ [54] whereas in 26 patients under anthracycline-based regimens, the median gestational age at delivery was 35 weeks (range 28-40 weeks) with two preterm deliveries [55].

The relationship between anthracyclines or in general chemotherapy during pregnancy and increased preterm labor is unclear: a possible contributing factor is maternal stress associated with cancer diagnosis and treatment [56]. In a retrospective study conducted in our gynecologic clinic, we suggested explaining to the mother that because many chemotherapeutic regimens including anthracyclines leave the fetus unchanged mothers should whenever possible avoid prematurity so as to reduce prematurity-induced medical complications at birth and in the long-term [57].

\section{Cardiac toxicity}

Cardiac toxicity is a specific feature of anthracycline toxicity [58] and emerged as a major concern after idarubicin-based chemotherapy administered during the second trimester or daunorubicin during the third trimester of pregnancy [32, 59]. The cardiac damage appears as heart dilatation, myocardial hypertrophy, dilated coronary arteries [60] or moderate right atrial and right ventricular dilatation with mildly depressed function, two small septal secundum atrial defects, and a small patent ductus arteriosus [61]. Followup examinations after 6 and 2 months found no residual signs of cardiomyopathy.

The safety profiles for DOX and EPI differed from those for idarubicin and daunomycin insofar as the first case reports and small case series suggested that this class of agent had no detectable effect on the fetal heart $[62,63]$. Otherwise, larger retrospective studies confirmed the cardiac safety of DOX and EPI regimens, administered during the second and third trimester in adjuvant, neoadjuvant and metastatic settings [55]: even a two-week dose-dense chemotherapy induced no cardiac toxicity [64]. Some studies on DOX in pregnancy reported a reduction in left ventricular wall thickness without heart defects or functional disorders [65].

Conversely, although EPI has been considered devoid of cardiotoxic effects [66-70] one report describes transient ventricular hypokinesia [71]. In another report from our gynecological institute supported by myocardial and placental evidence we showed that epirubicin cardiotoxicity had a causative role in the death of a twin who died shortly after receiving glucocorticoids for lung maturation [72]. Because glucocorticoids regulate in a complex manner the P-gp transport system at gene transcription and translation levels they could have contributed to the risk for damage from anthracycline exposure [73]. We also confirmed epirubicin cardiotoxicity by finding high troponin levels and transient left ventricular septal hypokinesia in the surviving newborn [72].

Two-dimensional echocardiography helped to evaluate fetal cardiac function including systolic and diastolic measures showing that anthracycline-based chemotherapy had no effect on ventricular diameters, septum thickness, ejection fraction and shortening fraction in the exposed fetuses [74].

In conclusion, cardiac toxicity during pregnancy or at birth therefore differs according to the type of anthracycline used. Despite rare toxicity reports [71, 72], studies in large populations $[55,64]$ imply that DOX and EPI have an acceptable safety profile.

\section{Late cardiac toxicity}

Older studies used two-dimensional echocardiography to calculate fractional shortening recommended as the best method to evaluate late cardiac toxicity in patients with cancer who received anthracyclines. This imaging technique showed that anthracyclines given for hematological malignancies during pregnancy induced no cardiac damage, even at follow-up repeated for 20 years every 5 years after birth until 29 years of age [75]. New echocardiographic equipment now under development might visualize earlier changes.

An observational study used speckle-tracking echocardiography, a recently developed technique for characterizing and quantifying myocardial deformation, in children $>5$ years old whose mothers had received anthracyclines during pregnancy. In this case-control study this technique found the use of anthracyclines for hematological malignancies during pregnancy was not associated with differences between case and control groups in fraction shortening, interventricular septum, left ventricular posterior wall, left ventricular end-diastolic diameter, left ventricular ejection fraction, and right ventricular end-diastolic diameter [76].

In an important multicenter observational case-control study assessing children who were prenatally exposed mainly to anthracycline-based chemotherapy at birth (53 
children), at age18 months, $5-6,8-9,11-12,14-15$, or 18 years, ECG measurements detected neither arrhythmia nor conduction abnormalities. The echocardiographic examination found a clinically smaller but statistically significant ejection fraction, fraction shortening and interseptal thickness decrease in the patient group than in the control group [77]. All patients were within the normal ECG range without any structural defects. Similarly, in another study, the echocardiographic assessment at 36 months in 47 children exposed to anthracyclines, failed to show signs of early cardiac remodeling, with normal wall thicknesses and chamber dimensions, and all systolic and diastolic function measurements came within normal ranges [78].

\section{Late neurodevelopmental toxicity}

As a gatekeeper for protecting the central nervous system, the cerebral microvessel endothelium forms the blood-brain barrier (BBB). Data acquired in recent years suggest that the $\mathrm{BBB}$ is active since fetal life and efficiently protects the immature brain [79]. In addition to the cellular level, several molecular mechanisms help to enhance selectivity in permitting materials to pass from the blood into the CNS. P-gp at the BBB can exert a profound effect on the ability of some drugs such as cardiovascular drugs to enter the brain. Abnormal activity involving the signaling pathways responsible for inducing functional efflux protection in blood-brain interfaces could induce influential changes in how the fetal brain is exposed to undesired substrates, eventually preventing the brain from developing normally. [80].

The existence of a protective barrier explains reassuring data suggesting that anthracyclines administered during pregnancy leave fetal neurodevelopment unchanged. After a median 18.7-year follow-up, anthracyclines administered for hematological malignancies during pregnancy had no effect on growth, development, hematological, cytogenetic, neurological, psychological variables, and learning disorders [81]. The aforementioned multicenter observational case-control study starting from 18 months, used clinical neurological examinations and tests assessing the general cognitive functioning level (Bayley or intelligence quotient [IQ] test) on a child cohort. At 5 years tests were completed by audiometry, the Auditory Verbal Learning Test, and Children's Memory Scale subtasks, and the Test of Everyday Attention for Children. At a median 24month follow-up average IQ scores increased by 11.1 points for each month increase in pregnancy duration but neurocognitive outcomes were within normal ranges [77]. In a small group, most children exposed prenatally to anthracycline-based chemotherapy exhibited no significant differences in cognitive ability, school performance, or behavioral competence [82].

In conclusion, although late anthracyline-induced cardiac and neurological toxicity raise little concern, patients need long-term follow-up to detect subtle changes during life before they become more severe.

\section{Conclusion}

Cancer in pregnancy is a clinical and ethical dilemma. The care provider has to manage two lives: the life of a woman suffering from a disease that if left untreated is likely to progress, and the life of a fetus exposed to damage from maternal chemotherapies administered.

Pregnant women are reluctant to receive chemotherapy because they fear its possible deleterious effects on the developing fetus even though current research implies that the placenta acts as a barrier thereby guaranteeing low transplacental anthracycline transfer.

Convincing evidence shows that chemotherapy given during the second and third trimesters of pregnancy is safe but anthracycline-based chemotherapy regimens raise concerns related to fetal cardiac toxicity.

Anthracyclines induce cardiotoxicity in the fetus first because fetal cardiac tissue is especially vulnerable to free radical damage owing to low cardiomyocyte tolerance to changes in the oxidant-antioxidant system, and also because embryonic and fetal myocytes grow and develop fully only later during prenatal life. Hence, fetuses exposed to anthracycline during pregnancy might later become patients at risk for premature cardiovascular disease during adulthood.

Despite growing evidence that anthracycline-based therapy is safe and effective, certain anthracycline drug classes continue to raise doubts. Whereas DOX and EPI have acceptable safety profiles, reported idarubicin teratogenicity warns against its use for pregnant mothers with cancer, especially hematologic cancer, unless no other option exists.

Hence pregnant women receiving anthracycline-based chemotherapy should undergo regular diagnostic imaging with the newly available techniques to detect damage early, and allow alternative therapeutic options. While we await new research to dispel uncertainty on the potential long-term effects of in utero anthracycline, patients need regular follow-up to detect late, subtle anthracyline-induced cardiac and neurological toxicity changes over time.

An equally important concern for obstetricians and gynecologists is that when pregnant women receive drugs that inhibit or induce P-gp, drug interactions may alter placental P-gp barrier function and subsequently change fetal exposure. Hence, giving glucocorticoids to prevent lung immaturity may hamper placental EPI metabolism, ultimately increasing its toxicity by reducing Pgp expression on the placental surface.

Some fetuses, such as those with intrauterine growth retardation, are more vulnerable and require more intensive monitoring owing to factors associated with a compromised 
placental supply of nutrients and oxygen that involves altered metabolic changes in pregnancy, and chronic inflammation. These babies may have an increased risk for damage from anthracycline exposure.

Anthracycline exposure may increase the risk of preterm labor. To minimize prematurity-induced complications, doctors who care for pregnant women should avoid inducing labor without any obstetrical indications.

Knowing more about the biological pathways regulating placental transport during fetal development and understanding how oxidative stress, inflammation and drugs modulate them, may open the way for tailored drug administration. For example, in animal experiments, when low P-gp-induced expression caused severe oxidative injuries in placentas from the fetal cardiac rat model, giving vitamin $\mathrm{C}$ reduced oxidative stress and rebuilt placental protective mechanisms [83].

P-gp at the BBB can prevent some drugs from entering the brain. Studying the BBB may open up new opportunities for tailoring anticancer therapy to improve or restore neuroprotective functions in the blood-brain interfaces thus preventing intrauterine injuries from anticancer therapy.

Finally, analyzing the pharmacokinetic features underlying gestation-induced changes will make it easier to adjust chemotherapy dose regimens.

\section{Abbreviations \\ ABVD: DOX-bleomycin-vinblastine-dacarbazine; BBB: Blood-brain-barrier; BCRP: Breast cancer resistance protein; DOX: Doxorubicin; EPI: Epirubicin; FAC: Fluorouracil-DOX-cyclophosphamide; FEC: Fluorouracil-EPI- cyclophosphamide; NADPH: Nicotinamide adenine dinucleotide phosphate; PARP: Poly(ADP-ribose) polymerase; P-gp: P-glycoprotein; PL: Pegylated}

\section{Acknowledgments}

We thank Alice Crossman for precious support in revising the English language.

\section{Funding}

No funding to declare

Availability of data and materials

Not applicable.

\section{Authors' contributions}

MFM conceived and drafted the manuscript. PS revised the manuscript. AN helped to revise the manuscript. All authors read and approved the final manuscript.

\section{Ethics approval and consent to participate}

Not applicable.

\section{Consent for publication \\ Not applicable.}

\section{Competing interests}

The authors declare that they have no competing interests.

\section{Publisher's Note}

Springer Nature remains neutral with regard to jurisdictional claims in published maps and institutional affiliations.

\section{Author details}

'Department of Gynecologic Obstetrics and Urologic Sciences, University Sapienza Rome, Viale del Policlinico, 15500161 Rome, Italy. ${ }^{2}$ Department of Surgery "Pietro Valdoni", University Sapienza Rome, Viale del Policlinico, 155 00161 Rome, Italy. ${ }^{3}$ Department of Clinical and Molecular Medicine,

University Sapienza Rome, Via di Grottarossa 1035/1039, 00189 Rome, Italy.

${ }^{4}$ Italian Diabetic and Pregnancy Study Group, Rome, Italy.

Received: 18 December 2016 Accepted: 13 November 2017

Published online: 21 November 2017

\section{References}

1. Albright $\mathrm{CM}$, Wenstrom KD. Malignancies in pregnancy. Best Pract Res Clin Obstet Gynaecol. 2015; doi:10.1016/j.bpobgyn.2015.10.004.

2. Fecondità in ripresa e calendario riproduttivo posticipato. National Institute of Statistics 2013. https://www.istat.it/it/files/2014/03/Noi-Italia-2014.pdf. Accessed 31 Mar 2016.

3. Genin AS, Lesieur B, Gligorov J, Antoine M, Selleret L, Rouzier R. Pregnancyassociated breast cancers: do they differ from other breast cancers in young women? Breast. 2012;21:550-5.

4. Langer A, Mohallem M, Stevens D, Rouzier R, Lerebours F, Chérel P. A single-institution study of 117 pregnancy-associated breast cancers (PABC): presentation, imaging, clinicopathological data and outcome. Diagn Interv Imaging. 2014:95:435-41.

5. Abadi U, Koren G, Lishner M. Leukemia and lymphoma in pregnancy. Hematol Oncol Clin North Am. 2011;25:277-91.

6. Minotti G, Menna P, Salvatorelli E, Cairo G, Gianni L. Anthracyclines: molecular advances and pharmacologic developments in antitumor activity and cardiotoxicity. Pharmacol Rev. 2004;56(2):185-229. Review

7. Kizek R, Adam V, Hrabeta J, Eckschlager T, Smutny S, Burda JV, et al. Anthracyclines and ellipticines as DNA-damaging anticancer drugs: recent advances. Pharmacol Ther. 2012;133(1):26-39. doi:10.1016/.jpharmthera.2011. 07.006. Epub 2011 Aug 3. Review.

8. Lyu YL, Kerrigan JE, Lin CP, Azarova AM, Tsai YC, Ban Y, et al. Topoisomerase 11 beta mediated DNA double-strand breaks implications in doxorubicin cardiotoxicity and prevention by dexrazoxane. Cancer Res. 2007;67:8839-46.

9. Mizutani H, Tada-Oikawa S, Hiraku Y, Kojima M, Kawanishi S. Mechanism of apoptosis induced by doxorubicin through the generation of hydrogen peroxide. Life Sci. 2005;76(13):1439-53. Epub 2005 Jan 20

10. Xu X, Sutak R, Richardson DR. Iron chelation by clinically relevant anthracyclines: alteration in expression of iron-regulated genes and atypical changes in intracellular iron distribution and trafficking. Mol Pharmacol. 2008;73(3):833-44. Epub 2007 Nov 20

11. Ichikawa Y, Ghanefar M, Bayeva M, Wu R, Khechaduri A, Naga Prasad SV, et al. Cardiotoxicity of doxorubicin is mediated through mitochondrial iron accumulation. J Clin Invest. 2014;124(2):617-30. doi:10.1172/JC172931. Epub 2014 Jan 2

12. Patanè S. Cardiotoxicity: anthracyclines and long-term cancer survivors. Int J Cardiol. 2014;176:1326-8.

13. Nikitovic D, Juranek I, Wilks MF, Tzardi M, Tsatsakis A, Tzanakakis GN. Anthracycline-dependent cardiotoxicity and extracellular matrix remodeling. Chest. 2014;146:1123-30.

14. Sauer H, Rahimi G, Hescheler J, Wartenberg M. Role of reactive oxygen species and phosphatidylinositol 3-kinase in cardiomyocyte differentiation of embryonic stem cells. FEBS Lett. 2000;476(3):218-23.

15. Siedner S, Krüger M, Schroeter M, Metzler D, Roell W, Fleischmann BK, et al. Developmental changes in contractility and sarcomeric proteins from the early embryonic to the adult stage in the mouse heart. J Physiol. 2003;548:493-505.

16. Mr S, Paxton JW, Keelan JA. Drug transfer and metabolism by the human placenta. Clin Pharmacokinet. 2004:43:487-514.

17. Myllynen $P$, Pasanen $M$, Vähäkangas $K$. The fate and effects of xenobiotics in human placenta. Expert Opin Drug Metab Toxicol. 2007;3(3):331-46.

18. Staud F, Cerveny L, Ceckova M. Pharmacotherapy in pregnancy; effect of $A B C$ and SLC transporters on drug transport across the placenta and fetal drug exposure. J Drug Target. 2012;20:736-63.

19. Eskholi T, Sheiner E, Ben-Zvi Z, Holcberg G. Drug transport across the placenta. Curr Pharm Biotechnol. 2011;12(5):707-14. Review

20. Burger H, Foekens JA, Look MP, Meijer-van Gelder ME, Klijn JG, Wiemer EA. RNA expression of breast cancer resistance protein, lung resistance-related protein, multidrug resistance-associated proteins 1 and 2, and multidrug 
resistance gene 1 in breast cancer: correlation with chemotherapeutic response. Clin Cancer Res. 2003;9(2):827-36.

21. Vähäkangas $K$, Myllynen $P$. Drug transporters in the human blood-placental barrier. Br J Pharmacol. 2009;158(3):665-78. Epub 2009 Sep 25

22. Walker N, Filis P, Soffientini U, Bellingham M, O'Shaughnessy PJ, Fowler PA. Placental transporter localization and expression in the human: the importance of species, sex, and gestational age differences. Biol Reprod. 2017;96(4):733-42. doi:10.1093/biolre/iox012.

23. Wang $H$, Unadkat JD, Mao Q. Hormonal regulation of BCRP expression in human placental BeWo cells. Pharm Res. 2008;25:444-52.

24. Morgan ET, Goralski KB, Piquette-Miller M, Renton KW, Robertson GR, Chaluvadi MR. Regulation of drug-metabolizing enzymes and transporters in infection, inflammation, and cancer. Drug Metab Dispos. 2008;36:205-16.

25. Iqbal M, Audette MC, Petropoulos S, Gibb W, Matthews SG. Placental drug transporters and their role in fetal protection. Placenta. 2012;33(3):137-42. doi:10.1016/j.placenta.2012.01.008. Epub 2012 Jan 20

26. De Lena M, Brambilla C, Morabito A, Bonadonna G. Adriamycin plus vincristine compared to and combined with cyclophosphamide, methotrexate, and 5-fluorouracil for advanced breast cancer. Cancer. 1975;35(4):1108-15.

27. D'Incalci M, Broggini M, Buscaglia M, Pardi G. Transplacental passage of doxorubicin. Lancet. 1983;1:75.

28. Karp Gl, von Oeyen P, Valone F, Khetarpal VK, Israel M, Mayer RJ, et al. Doxorubicin in pregnancy: possible transplacental passage. Cancer Treat Rep. 1983:67:773-7.

29. Barni S, Ardizzoia A, Zanetta G, Strocchi E, Lissoni P, Tancini G. Weekly doxorubicin chemotherapy for breast cancer in pregnancy. A case report. Tumori 1992;78:349-50.

30. Grohard P, Akbaraly JP, Saux MC, Gimenez S, Robert J, Brachet-Liermain A, et al. Transplacental passage of doxorubicin. J Gynecol Obstet Biol Reprod (Paris). 1989;18(5):595-600.

31. Gaillard B, Leng JJ, Grellet J, Ducint D, Saux MC. Transplacental passage of epirubicin. J Gynecol Obstet Biol Reprod. 1995;24(1):67-8.

32. German N, Goffinet F, Goldwasse R. Anthracyclines during pregnancy: embryo-fetal outcome in 160 patients. Ann Oncol. 2004;15(1):146-50.

33. Van Calsteren K, Verbesselt R, Van Bree R, Heyns L, de Bruijn E, de Hoon J, et al. Substantial variation in transplacental transfer of chemotherapeutic agents in a mouse model. Reprod Sci. 2011;18(1):57-63. doi:10.1177/ 1933719110379650. Epub 2010 Sep 8

34. Gziri MM, Pokreisz P, De Voz R, Verbeken E, Debiève F, Mertens L, et al. Fetal rat hearts do not display acute cardiotoxicity in response to maternal doxorubicin treatment. J Pharmacol Exp Ther 2013;346:362-369.

35. Van Calsteren K, Verbesselt R, Beijnen J, Devlieger R, De Catte L, Chai DC, et al. Transplacental transfer of anthracyclines, vinblastine, and 4-hydroxycyclophosphamide in a baboon model. Gynecol Oncol. 2010;119(3):594600. doi:10.1016/j.ygyno.2010.08.019. Epub 2010 Sep 17

36. Ma P, Dong X, Swadley CL, Gupte A, Leggas M, Ledebur HC, et al. Development of idarubicin and doxorubicin solid lipid nanoparticles to overcome Pgp-mediated multiple drug resistance in leukemia. J Biomed Nanotechnol. 2009;5(2):151-61.

37. Barenholz Y. Doxil ${ }^{\circledR}$-the first FDA-approved nano-drug: lessons learned. J Control Release. 2012;160(2):117-34. doi:10.1016/j.jconrel.2012.03.020. Epub 2012 Mar 29. Review

38. Soininen SK, Repo JK, Karttunen V, Auriola S, Vähäkangas KH, Ruponen M. Human placental cell and tissue uptake of doxorubicin and its liposomal formulations. Toxicol Lett. 2015;239(2):108-14. doi:10.1016/j.toxlet.2015.09. 011. Epub 2015 Sep 14

39. Lin B, Gupta D, Heinen CD. Human pluripotent stem cells have a novel mismatch repair-dependent damage response. J Biol Chem. 2014;289(35): 24314-24. doi:10.1074/jbc.M114.570937. Epub 2014 Jul 10

40. Cardonick $E$, lacobucci $A$. Use of chemotherapy during human pregnancy. Lancet Oncol. 2004;5(5):283-91. Review

41. Leyder M, Laubach M, Breugelmans M, Keymolen K, De Greve J, Foulon W. Specific congenital malformations after exposure to cyclophosphamide, epirubicin and 5-fluorouracil during the first trimester of pregnancy. Gynecol Obstet Investig. 2011;71:141-4.

42. Bell DJ, Kerr DJ. Pharmacokinetic considerations in the use of anticancer drugs during pregnancy: challenges and new developments. Expert Opin Drug Metab Toxicol. 2015;11(9):1341-4. doi:10.1517/17425255.2015.1055247. Epub 2015 Jun 22
43. Van Hasselt JGC, van Calsteren K, Heyns L, Han S, Mhallem Gziri M, Schellens $\mathrm{JH}$, Beijnen $\mathrm{JH}$, et al. Optimizing anticancer drug treatment in pregnant cancer patients: pharmacokinetic analysis of gestation-induced changes for doxorubicin, epirubicin, docetaxel and paclitaxel. Ann Oncol. 2014;25:2059-65.

44. Ryu RJ, Eyal S, Kaplan HG, Akbarzadeh A, Hays K, Puhl K, et al. Pharmacokinetics of doxorubicin in pregnant women. Cancer Chemother Pharmacol. 2014;73(4): 789-97. doi:10.1007/s00280-014-2406-z. Epub 2014 Feb 15

45. Chang A, Patel S. Treatment of acute myeloid leukemia during pregnancy. Ann Pharmacother. 2015;49(1):48-68. doi:10.1177/1060028014552516. Epub 2014 Sep 25

46. Niedermeier DM, Frei-Lahr DA, Hall PD. Treatment of acute myeloid leukemia during the second and third trimesters of pregnancy. Pharmacotherapy. 2005;25(8):1134-40.

47. Giacalone PL, Laffargue F, Bénos $P$. Chemotherapy for breast carcinoma during pregnancy: a French national survey. Cancer. 1999;86:2266-72.

48. Peres RM, Sanseverino MT, Guimarães JL, Coser V, Giuliani L, Moreira RK, et al. Assessment of fetal risk associated with exposure to cancer chemotherapy during pregnancy: a multicenter study. Braz J Med Biol Res. 2001;34:1551-9.

49. Loibl S, Han SN, von Minckwitz G, Bontenbal M, Ring A, Giermek J, et al. Treatment of breast cancer during pregnancy: an observational study. Lancet Oncol. 2012;13(9):887-96. doi:10.1016/S14702045(12)70261-9. Epub 2012 Aug 16

50. Pregnancy and Breast Cancer. Royal College of Obstetricians and Gynaecologists. https://www.rcog.org.uk/en/guidelines-research-services/ guidelines/gtg12/.

51. Loibl S, Schmidt A, Gentilini O, Kaufman B, Kuhl C, Denkert C, et al. Breast cancer diagnosed during pregnancy: adapting recent advances in breast cancer Care for Pregnant Patients. JAMA Oncol. 2015;1(8):1145-53. doi:10. 1001/jamaoncol.2015.2413.

52. Berry DL, Theriault RL, Holmes FA, Parisi VM, Booser DJ, Singletary SE, et al. Management of breast cancer during pregnancy using a standardized protocol. J Clin Oncol. 1999;17:855-61.

53. Hahn KM, Johnson PH, Gordon N, Kuerer H, Middleton L, Ramirez Q, et al. Treatment of pregnant breast cancer patients and outcomes of children exposed to chemotherapy in utero. Cancer. 2006;107(6):1219-26.

54. Cardonick E, Dougherty R, Grana G, Gilmandyar D, Ghaffar S, Usmani A. Breast cancer during pregnancy: maternal and fetal outcomes. Cancer J. 2010;16:76-82.

55. Azim Jr, H.A., Peccatori, F.A., Scarfone, G., Acaia, B., Rossi, P., Cascio, R. et al. (2008) Anthracyclines for gestational breast cancer: course and outcome of pregnancy. Ann Oncol. 19: 15111512

56. Glynn LM, Schetter CD, Hobel CJ, Sandman CA. Pattern of perceived stress and anxiety in pregnancy predicts preterm birth. Health Psychol. 2008;27:43-51.

57. Framarino-Dei-Malatesta M, Piccioni MG, Brunelli R, lannini I, Cascialli G, Sammartino P. Breast cancer during pregnancy: a retrospective study on obstetrical problems and survival. J Obstet Gynecol Reprod Biol. 2014;173: 48-52. doi:10.1016/j.ejogrb.2013.11.017. Epub 2013 Nov 28

58. Serrano JM, González I, Del Castillo S, Muñiz J, Morales LJ, Moreno F, et al. Diastolic dysfunction following anthracycline-based chemotherapy in breast cancer patients: incidence and predictors. Oncologist. 2015;20(8):864-72. https://doi.org/10.1634/theoncologist. 2014-0500. Epub 2015 Jul 16

59. Achtari C, Hohlfeld P. Cardiotoxic transplacental effect of idarubicin administered during the second trimester of pregnancy. Am J Obstet Gynecol. 2000;183:511-2.

60. Baumgärtner AK, Oberhoffer R, Jacobs VR, Ostermayer E, Menzel H, Voigt M, et al. Reversible foetal cerebral ventriculomegaly and cardiomyopathy under chemotherapy for maternal AML. Onkologie. 2009;32:40-3.

61. Siu BL, Alonzo MR, Vargo TA, Fenrich AL. Transient dilated cardiomyopathy in a newborn exposed to idarubicin and all trans-retinoic acid (ATRA) early in the second trimester of pregnancy. Int J Gynecol Cancer. 2002;12:399-402.

62. Turchi JJ, Villasis C. Anthracyclines in the treatment of malignancy in pregnancy. Cancer. 1988:435-40.

63. Meyer-Wittkopf M, Barth H, Emons G, Schmidt S. Fetal cardiac effects of doxorubicin therapy for carcinoma of the breast during pregnancy: case report and review of the literature. Ultrasound Obstet Gynecol. 2001;18:62-6. 
64. Cardonick E, Gylmandiar D, Somer RA. Maternal and neonatal outcomes of dose-dense chemotherapy for breast cancer in pregnancy. Obstet Gynecol. 2012;120:1267-72.

65. Van Calsteren K, Berteloot P, Hanssens M, Vergote I, Amant F, Ganame J, et al. In utero exposure to chemotherapy: effect on cardiac and neurologic outcome. J Clin Oncol. 2006;24:e16-7.

66. Goldwasser F, Pico JL, Cerrina J, Fernandez H, Pons JC, Cosset JM, et al. Successful chemotherapy including epirubicin in a pregnant non-Hodgkin's lymphoma patient. Leuk Lymphoma. 1995;20(1-2):173-6.

67. Gadducci A, Cosio S, Fanucchi A, Nardini V, Roncella M, Conte PF, et al. Chemotherapy with epirubicin and paclitaxel for breast cancer during pregnancy: case report and review of the literature. Anticancer Res. 2003;23:5225-9.

68. Ginopoulos PV, Michail GD, Kourounis GS. Pregnancy associated breast cancer: a case report. Eur J Gynaecol Oncol. 2004;25:261-3.

69. Bodner-Adler B, Bodner K, Zeisler H. Breast cancer diagnosed during pregnancy. Anticancer Res. 2007;27:1705-7.

70. Peccatori FA, Azim HA Jr, Scarfone G, Gadducci A, Bonazzi C, Gentilini O, et al. Weekly epirubicin in the treatment of gestational breast cancer (GBC). Breast Cancer Res Treat. 2009;115:591-4.

71. Parodi E, Alluto A, Moggio G, Liberale V, Frigerio M, Sismondi P. Transient ventricular hypocinesia after in utero anthracyclines exposure: a case report and review of the literature. J Matern Fetal Neonatal Med. 2012;25:189-92.

72. Framarino-dei-Malatesta M, Perrone G, Giancotti A, Ventriglia F, Derme M, lannini l, et al. Epirubicin: a new entry in the list of fetal cardiotoxic drugs? Intrauterine death of one fetus in a twin pregnancy. Case report and review of literature. BMC Cancer. 2015;15:951. doi:10.1186/s12885-015-1976-4.

73. Petropoulos S, Gibb W, Matthews SG. Effect of glucocorticoids on regulation of placental multidrug resistance phosphoglycoprotein (P-gp) in the mouse. Placenta. 2010;31(9):803-10. doi:10.1016/j.placenta.2010.06.014. Epub 2010 Jul 23

74. Gziri MM, Debiève F, DE Catte L, Mertens L, Barrea C, Van Calsteren K, et al. Chemotherapy during pregnancy: effect of anthracyclines on fetal and maternal cardiac function. Acta Obstet Gynecol Scand. 2012;91(12):1465-8. doi:10.1111/j.1600-0412.2012.01524.x. Epub 2012 Nov 1

75. Avilés A, Neri N, Nambo MJ. Long-term evaluation of cardiac function in children who received anthracyclines during pregnancy. Ann Oncol. 2006; 17(2):286-8. Epub 2005 Nov 4

76. Avilès A, Nambo MJ, Huerta-Guzmàn J, Neri N, Cleto S. Speckletracking echocardiography to detect cardiac toxicity in children who received anthracyclines during pregnancy. Clin Lymphoma Myeloma Leuk. 2016;16(1):1-4.

77. Amant F, Van Calsteren K, Halaska MJ, Gziri MM, Hui W, Lagae L, et al. Longterm cognitive and cardiac outcomes after prenatal exposure to chemotherapy in children aged 18 months or older: an observational study. Lancet Oncol. 2012;13:256-64.

78. Amant F, Vandenbroucke T, Verheecke M, Fumagalli M, Halaska MJ, Boere I, et al. International network on cancer, infertility, and pregnancy (INCIP). Pediatric outcome after maternal cancer diagnosed during pregnancy. N Engl J Med. 2015;373:1824-34. doi:10.1056/NEJMoa1508913. Epub 2015 Sep 28.

79. Ben-Zvi A, Lacoste B, Kur E, Andreone BJ, Mayshar Y, Yan H, Gu C. Mfsd2a is critical for the formation and function of the blood-brain barrier. Nature. 2014; 509(7501):507-11. doi:10.1038/nature13324. Epub 2014 May 14

80. Strazielle N, Ghersi-Egea JF. Efflux transporters in blood-brain interfaces of the developing brain. Front Neurosci. 2015;9:21. doi:10.3389/fnins.2015. 00021. eCollection 2015. Review

81. Avilès $A$, Neri N. Hematological malignancies and pregnancy: a final report of 84 children who received chemotherapy in utero. Clin Lymphoma. 2001;2(3):173-7.

82. Cardonick EH, Gringlas MB, Hunter K, Greenspan J. Development of children born to mothers with cancer during pregnancy: comparing in utero chemotherapy-exposed children with nonexposed controls. Am J Obstet Gynecol. 2015;212(5):658.e1-8. doi:10.1016/j.ajog.2014.11.032. Epub 2014 Nov 27

83. Li Y, Fang J, Zhou K, Wang C, Mu D, Hua Y. Evaluation of oxidative stress in placenta of fetal cardiac dysfunction rat model and antioxidant defenses of maternal vitamin C supplementation with the impacts on P-glycoprotein. J Obstet Gynaecol Res. 2014;40(6):1632-42. doi:10.1111/jog.12389.

\section{Submit your next manuscript to BioMed Central and we will help you at every step:}

- We accept pre-submission inquiries

- Our selector tool helps you to find the most relevant journal

- We provide round the clock customer support

- Convenient online submission

- Thorough peer review

- Inclusion in PubMed and all major indexing services

- Maximum visibility for your research

Submit your manuscript at www.biomedcentral.com/submit 